\title{
Cretaceous World TCN: Digitizing the Western Interior Seaway at the Yale Peabody Museum
}

\author{
Elissa Martin ${ }^{\ddagger}$, Susan H. Butts ${ }^{\ddagger}$, Leanne Elder ${ }^{\ddagger}$, Lawrence F. Gall ${ }^{\ddagger}$, Christina Lutz ${ }^{\ddagger}$, Christopher A. \\ Norris ${ }^{\ddagger}$, Jessica Utrup ${ }^{\ddagger}$ \\ ‡ Yale Peabody Museum, New Haven, CT, United States of America
}

Corresponding author: Susan H. Butts (susan.butts@yale.edu)

Received: 23 Apr 2018| Published: 15 Jun 2018

Citation: Martin E, Butts S, Elder L, Gall L, Lutz C, Norris C, Utrup J (2018) Cretaceous World TCN: Digitizing the Western Interior Seaway at the Yale Peabody Museum. Biodiversity Information Science and Standards 2: e26115. https://doi.org/10.3897/biss.2.26115

\section{Abstract}

Yale Peabody Museum (YPM) is a partner in the Western Interior Seaway Thematic Collections Network (TCN), along with the University of Kansas (lead) and seven other institutions (National Science Foundation Award \# DBI-1601884). This project seeks to digitize the fossil organisms of the Western Interior Seaway, a shallow sea that covered inland North America from 100 to 65 million years ago. The resultant data will be a resource for K-16 education and will enable scientists to answer fundamental questions about the changing environment of a marine ecosystem during a key time in the history of life. The data generated will be ideal for use with an assortment of modern quantitative tools like paleoecological niche modeling (PaleoENM) and will help improve paleoclimate and paleoceanographic models.

Less than two years into this three-year project, the YPM has digitized nearly 70,000 Cretaceous fossils from the seaway. Specimens are georeferenced and most have multiple images. To achieve project goals, we have overcome obstacles of digitizing multi-specimen concretions and foraminifera microslides by developing high-throughput digitization workflows that incorporate the open-source Inselect program and scripts to streamline image naming, image formatting, and uploading to our Axiell EMu collection management system. 
To facilitate use of the data in K-16 environments, an easy to use collections interface has been built using the iDigPaleo platform (idigpaleo.org). Cretaceous World (cretaceousworl d.org) pulls data from iDigBio for all Cretaceous World TCN providers. Students can browse specimens using filters, rather than entering specific search terms. Navigation is simplified using common names harvested from the Encyclopedia of Life. Specimens are displayed as images accompanied by collection and locality data and plotted on a map. Registration provides access to tools supporting annotation, measurement, specimen record commenting, and social media sharing. Images can be curated as galleries and used for education. This includes sharing of galleries between students and teachers and PDF or PowerPoint exports.

Fifty-eight 3D models of vertebrates and invertebrates have been placed on morphosource.org and will be made available via a 3D embedded viewer on cretaceousworld.org for use in K-16 education. Undergraduate students from Dartmouth, Oberlin, Southern Connecticut State University, and Yale, have participated in the project and served as mentors for high school interns. These interns, recruited from the Peabody EVOLUTIONS afterschool program, gained first-hand experience in collections-based research, digitization, and imaging techniques, while learning about the science of paleontology and the process of curating museum collections, and researching and reconstructing food webs in this fascinating ancient ecosystem.

\section{Keywords}

digitization, paleontology, Cretaceous World TCN

\section{Presenting author}

Elissa Johnson

\section{Grant title}

Digitization TCN: Collaborative Research: The Cretaceous World: Digitizing Fossils to Reconstruct Evolving Ecosystems in the Western Interior Seaway 